\title{
Aa. Vv., Medieval Manuscripts in Transition. Tradition and Creative Recycling
}

\section{Maria Colombo Timelli}

\section{(2) OpenEdition}

1 Journals

\section{Édition électronique}

URL : http://journals.openedition.org/studifrancesi/8833

DOI : 10.4000/studifrancesi.8833

ISSN : 2421-5856

Éditeur

Rosenberg \& Sellier

\section{Édition imprimée}

Date de publication : 1 octobre 2008

Pagination : 433

ISSN : 0039-2944

\section{Référence électronique}

Maria Colombo Timelli, «Aa. Vv., Medieval Manuscripts in Transition. Tradition and Creative Recycling », Studi Francesi [En ligne], 155 (LII | II) | 2008, mis en ligne le 30 novembre 2015, consulté le 13 janvier 2021. URL : http://journals.openedition.org/studifrancesi/8833 ; DOI : https://doi.org/10.4000/ studifrancesi.8833

Ce document a été généré automatiquement le 13 janvier 2021.

\section{(c) 9 (i) $\Theta$}

Studi Francesi è distribuita con Licenza Creative Commons Attribuzione - Non commerciale - Non opere derivate 4.0 Internazionale. 


\title{
Aa. Vv., Medieval Manuscripts in Transition. Tradition and Creative Recycling
}

\author{
Maria Colombo Timelli
}

\section{RÉFÉRENCE}

Medieval Manuscripts in Transition. Tradition and Creative Recycling, Leuven University Press, 2006 («Medievalia Lovaniensia», Series I / Studia XXXVI).

1 Nous traitons ici des contributions concernant le $\mathrm{XV}^{\mathrm{e}}$ siècle, d'autres sont signalées dans la section «Medio Evo».

2 Virginie MINET-MAHY, Le recyclage des métaphores dans la littérature allégorique: de l'histoire du sens à la création poétique, pp. 197-218. Au sein d'une recherche bien plus vaste sur le retour des métaphores de l'Antiquité biblique et classique à la littérature poétique du Moyen Âge français, V.M.-M. étudie l'image de la harpe et de l'harmonie universelle dans l'œuvre de trois auteurs: Evrart de Conty, Jean Gerson (avec une attention spéciale pour l'iconographie du ms. BnF lat. 17487) et Jean Molinet (surtout le Naufrage de la Pucelle et le Petit traictiet de la harpe).

3 SUSie SPEAKMAN SUTCH, La production d'un manu-scrit du poème intitulé "Le Chevalier délibéré" d'Olivier de la Marche, pp. 241-260. Une comparaison minutieuse du texte, de la mise en page et de l'iconographie de deux manuscrits du Chevalier deliberé (Cambridge, Fitzwilliam Museum 166, et Paris, BnF, S.M.A.F. 80-11) montre bien que le second est une copie du premier. Reste à éclaircir la présence dans le ms. de la S.M.A.F. de l'Instruction d'un jeune prince de Guillebert de Lannoy: S.S.-S. avance l'hypothèse que celle-ci constitue le volet 'théorique' d'un miroir du prince offert à charles le Téméraire, alors que le poème d'olivier de la Marche proposerait les 'exempla' à suivre.

4 Tania VAN HEMELRYCK, "La Mutacion de Paix": L'évolution des figures exemplaires pacifiques dans la littérature française médiévale du xiv siècle au début du $\mathrm{xvi}^{e}$ siècle, pp. 309-321. Les 
figures exemplaires antiques, tant classiques que chrétiennes, «participent activement à l'élaboration d'une rhétorique de la paix» (p. 309). Quelques exemples tirés des poèmes d'Eustache Deschamps, de l'Epistre à la reine et du Ditié de Jehanne d'Arc de Christine de Pizan, des œuvres de Georges Chastelain (Louange à la Vierge, Epistre au duc de Bourgogne, Exposition sur verité mal prise et Livre de Paix), enfin de la Concorde du genre humain de Jean Lemaire, permettent à T.V.H. de conclure sur la fonction que ces auteurs attribuent à l'emploi de ces figures, qui concourt à légitimer leur discours pacifique.

Livia VISSER-FUCHS, The Manuscript of the "Enseignement de vraie noblesse" made for Richard Neville, Earl of Warwick, in 1464, pp. 337-362. Il s'agit du manuscrit Genève, BPU, fr. 166, manuscrit luxueux qui contient l'Enseignement de vraie noblesse, un traité que l'on peut assimiler aux nombreux miroirs de prince du $\mathrm{xv}^{\mathrm{e}}$ siècle. L.V.-F. tend à attribuer le texte à Hugues de Lannoy plutôt qu'à son frère Guillebert, et situe l'exécution de cet exemplaire dans le cadre de l'activité diplomatique qui se déploya entre Angleterre, France et Bourgogne au cours des années 1461-1465. 